\title{
The Determination of the Plaque Burden on the Carotid Artery With Ultrasound Significantly Improves the Risk Prediction in Middle-Aged Subjects Compared to PROCAM: An Outcome Study
}

\author{
Ansgar Adams $^{\mathrm{a}, \mathrm{d}}$, Waldemar Bojara ${ }^{\mathrm{b}}$, Michel Romanens ${ }^{\mathrm{c}}$
}

\begin{abstract}
Background: There are only few data about the predictive value of atherosclerosis imaging beyond traditional risk calculators in younger subjects.

Methods: We assessed cardiovascular risk prediction with the PROCAM (the Prospective Cardiovascular Munster Study) risk equation and with carotid plaque imaging (determination of total plaque area (TPA) and the maximum plaque thickness with ultrasound) in subjects without known cardiovascular diseases. The follow-up was generated during follow-up examinations as part of preventive medical examinations or by telephone calls.
\end{abstract}

Results: In 2,508 subjects aged 35 - 64 years $(50 \pm 8$ years, 34\% women), $132(5.3 \%)$ cardiovascular events occurred (42 myocardial infarction, 17 bypass surgery, 31 stent implantation, 42 coronary artery disease defined by invasive angiography) during a mean follow-up period of $5.4(1-12)$ years. TPA in combination with the maximum plaque thickness (type III - IV b plaques ) tended to be superior compared to TPA, and both plaque imaging methods were superior to PROCAM: area under the curve (AUC) 0.9 (95\% confidence interval (CI): 0.91 - 0.89 ) vs. 0.89 (95\% CI: 0.90 - 0.88), $\mathrm{P}=0.2$ vs. 0.82 (95\% CI: 0.84 - 0.81), $\mathrm{P}=0.001$; positive predictive value (PPV) $27 \%$ (95\% CI: 0.31 - 0.22 ) vs. $19 \%$ (95\% CI: 0.22 - 0.16) vs. $19 \%$ (95\% CI: 0.27 - 0.13 ).

Conclusions: Amount of carotid plaque assessed by carotid plaque imaging significantly improves cardiovascular risk prediction beyond the PROCAM risk equation.

Manuscript submitted April 15, 2020, accepted April 24, 2020

Published online June 3, 2020

${ }^{a} B \cdot A \cdot D$ Gesundheitsvorsorge und Sicherheitstechnik GmbH Zentrum Koblenz, Koblenz, Germany

${ }^{b}$ Medizinische Klinik Kardiologie Koblenz, Gemeinschaftsklinikum Kemperhof II, Koblenz, Germany

${ }^{c}$ Vascular Risk Foundation (Varifo), Olten, Switzerland

${ }^{\mathrm{d} C o r r e s p o n d i n g ~ A u t h o r: ~ A n s g a r ~ A d a m s, ~ B ~} \cdot A \cdot D$ Health Care and Safety Technology Centre GmbH, Koblenz, Germany.

Email: ansgar.adams@bad-gmbh.de

doi: https://doi.org/10.14740/cr1067
Keywords: Total plaque area; Carotid ultrasound; Cardiovascular risk; Coronary disease

\section{Introduction}

It was examined how well coronary artery disease (CAD) can be predicted by an ultrasound examination of the carotid artery. For this purpose, the sum of all plaque areas (total plaque area (TPA) and the maximum plaque thickness were determined. The prediction quality was compared to that of the PROCAM (the Prospective Cardiovascular Munster Study) score.

Previous studies have shown that advanced atherosclerosis of the carotid artery is associated with an increased risk of cardiovascular diseases [1-16]. An outcome study that works with age-dependent cut-off values for the plaque area combined with the maximum plaque thickness is new.

\section{Materials and Methods}

In 2,386 healthy men and 1,423 healthy women aged $35-64$ years, the sum of all plaque areas (TPA), the maximum plaque thickness and the PROCAM risk were determined. A portable ultrasound device from Kontron Medical, Type Imagic Agile, with a $10 \mathrm{MHz}$ linear transducer was used. The measurement method was carried out as previously published study $[17,18]$ : a low risk corresponds to a type I and type IIa finding on ultrasound, an intermediate risk to a type IIb and IVa finding, and a high risk to a type III and IVb finding. The PROCAM risk was calculated using the published calculator of the Assmann Foundation [19].

All studies were evaluated with the approval of the responsible ethics committee.

\section{Results}

A follow-up is available for 2,508 (65.8\%) subjects. In these subjects (50 \pm 8 years, $34 \%$ women) $132(5.3 \%)$ cardiovas- 
cular events occurred (42 myocardial infarctions, 17 bypass surgery, 31 stent implantations, 42 coronary artery diseases defined by invasive angiography) during a mean follow-up time of $5.4(1-12)$ years.

\section{Analysis for the follow-up of 2,508 healthy men and women}

In the receiver operating characteristic (ROC) analysis to predict cardiovascular events, the area under the curve (AUC) for type III and IVb was 0.9 (95\% confidence interval (CI): 0.91 - 0.89$)$ vs. 0.89 (95\% CI: $0.90-0.88 ; \mathrm{P}=0.20)$ for the TPA without considering the plaque thickness vs. $0.82(95 \% \mathrm{CI}$ : 0.84 - $0.81 ; \mathrm{P}=0.001$ ) for PROCAM (Fig. 1).

The four-field table showed a sensitivity of $85 \%$ (95\% CI: $0.90-0.78)$ and a specificity of $87 \%(95 \%$ CI: $0.88-0.86)$, a positive predictive value (PPV) of $27 \%$ (95\% CI: $0.31-0.22)$ and a negative predictive value (NPV) of 99\% (95\% CI: 0.99 0.99 ) with a prevalence of $5 \%$.

For the TPA with a cut-off from $80 \mathrm{~mm}^{2}$ (TPA 80), the sensitivity was $84 \%$ (95\% CI: $0.90-0.77$ ), the specificity $80 \%$ (95\% CI: 0.82 - 0.78), the PPV 19\% (95\% CI: 0.22 - 0.16) and the NPV 99\% (95\% CI: $0.99-0.98)$ and for the PROCAM score a sensitivity of $21 \%(95 \%$ CI: $0.29-0.15)$, a specificity of $95 \%$ (95\% CI: 0.96 - 0.94), a PPV of 19\% (95\% CI: 0.27 0.13 ) and a NPV of $96 \%$ (95\% CI: $0.96-0.95)$ (Table 1).

In patients with a cardiovascular event, $11(8.3 \%)$ of 132 patients had a low risk on ultrasound, nine $(6.8 \%)$ had an intermediate risk, and $112(84.9 \%)$ a high risk (definition of ultrasound risk see Fig. 2).

According to PROCAM, $57(43.2 \%)$ of the 132 patients had a low $<10 \%$ risk, $47(35.6 \%)$ an intermediate $10-19 \%$ risk and $28(21.2 \%)$ a high $\geq 20 \%$ risk (Fig. 2$)$.

In addition to the outcome data, coronary angiography results were available in 297 subjects.

For these, the four-field table for the prediction of CAD showed a sensitivity of $85 \%(95 \% \mathrm{CI}: 0.90-0.78)$ in ultrasound vs. $84 \%$ (95\% CI: $0.90-0.77)$ in TPA 80 vs. $21 \%(95 \%$ CI: $0.29-0.15)$ in PROCAM; a specificity of $62 \%(95 \% \mathrm{CI}$ : 0.70 - 0.55$)$ vs. $48 \%$ (95\% CI: 0.56 - 0.41$)$ vs. $84 \%$ (95\% CI: 0.89 - 0.77$)$; a PPV of $64 \%$ (95\% CI: $0.71-0.57)$ vs. $57 \%$ (95\% CI: $0.64-0.49)$ vs. $51 \%(95 \%$ CI: $0.65-0.37)$; and a NPV of $84 \%(95 \%$ CI: $0.90-0.76)$ vs. $79 \%$ (95\% CI: 0.87 $0.70)$ vs. $57 \%$ (95\% CI: 0.63 - 0.51).

With a cut-off for a coronary stenosis $\geq 30 \%$, the sensitivity for the ultrasound resulted in $86 \%$ (95\% CI: $0.91-0.80)$, a specificity of $71 \%$ (95\% CI: $0.78-0.63)$, a PPV of $76 \%(95 \%$ CI: 0.82 - 0.69), and a NPV of $83 \%$ (95\% CI: $0.89-0.75)$.

With type III or IVb findings on ultrasound (high risk), only $12 \%$ had smooth vessels, $23.6 \%$ had sclerosis to $40 \%$ stenosis and $64.4 \%$ had CAD (Fig. 3).

\section{Discussion}

Atherosclerosis is an inflammatory disease of the arteries and continues to be a major cause for morbidity and mortality in the industrialized nations. Fatty streaks can be found in arteries
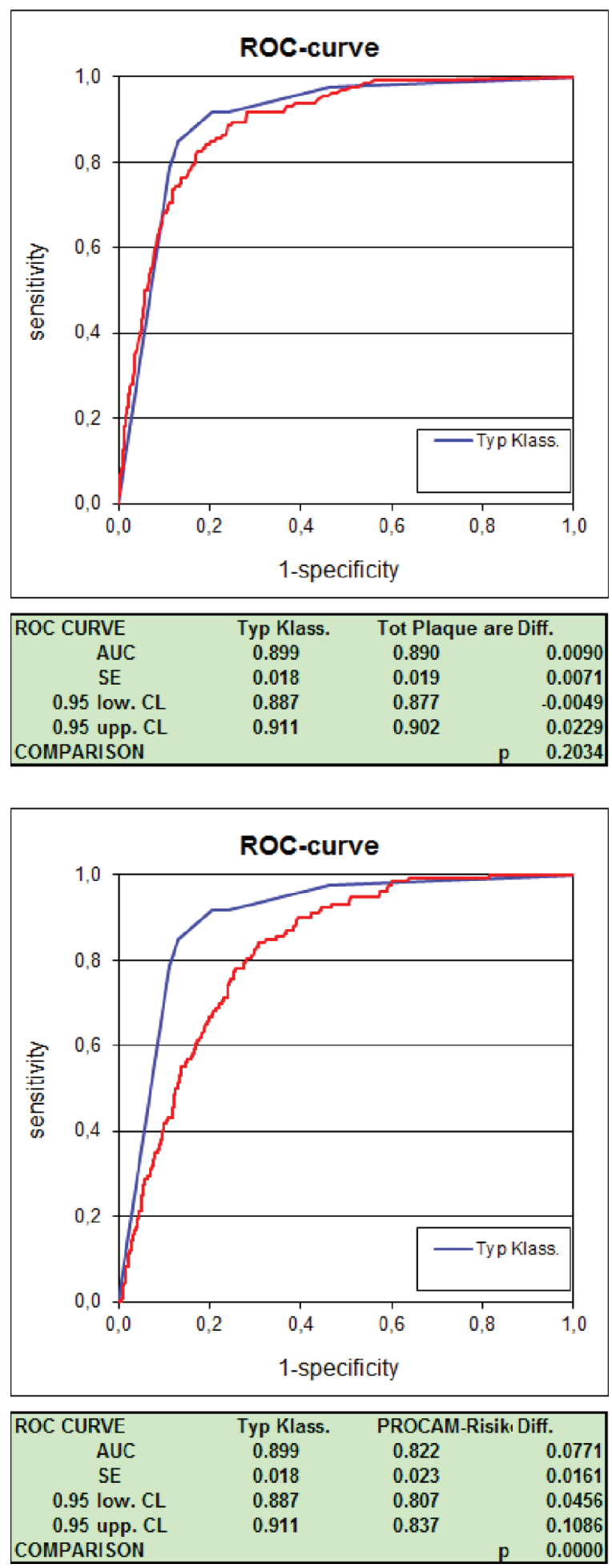

Figure 1. Receiver operating characteristic (ROC) comparison of types I - IVb vs. TPA vs. PROCAM. TPA: total plaque area (carotid plaque); PROCAM: the Prospective Cardiovascular Munster Study.

already at the age of 20 years, and progression of atherosclerosis often remains undetected until clinical events such as acute coronary syndrome (ACS), chronic coronary syndrome (CCS), 
Table 1. Four-Field Table for the Prediction of a Coronary Stenosis for TPA/Maximum Plaque Thickness vs. TPA 80 vs. PROCAM

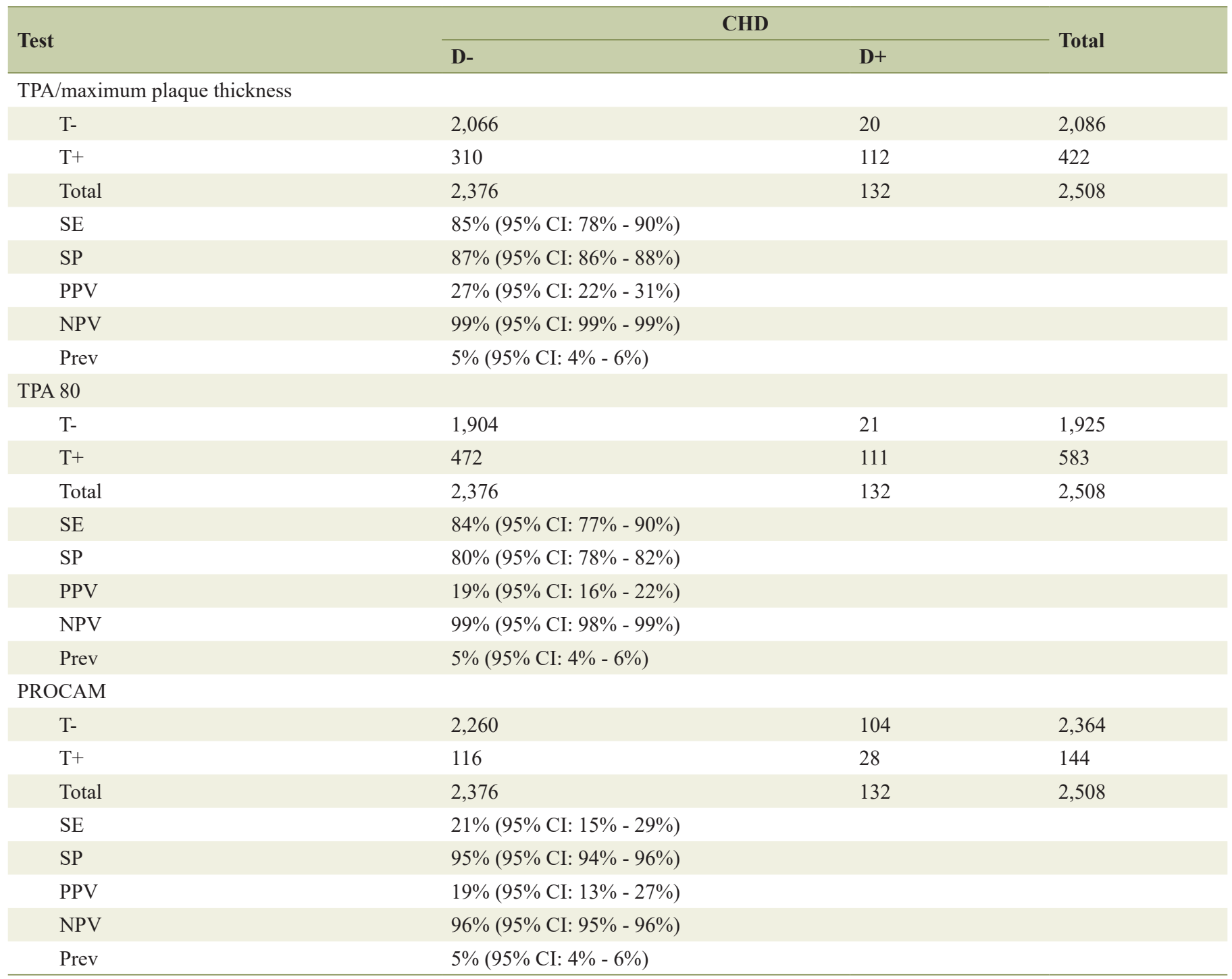

TPA: total plaque area (carotid plaque); CHD: coronary heart disease; PROCAM: the Prospective Cardiovascular Munster Study; Cl: confidence interval; SE: sensitivity; SP: specificity; PPV: positive predictive value; NPV: negative predictive value; Prev: prevalence.

apoplexy, and peripheral artery disease (PAD) occur.

In order to assess the quality of a diagnosis, the sensitivity and specificity or the results of the ROC analysis are usually given in studies. These values are not dependent on the prevalence of the disease, and can therefore show good results, although the PPV is low [20]. The lower the prevalence of the disease is, the higher the false positive rate with a low PPV. The opposite applies to the NPV. Screening inevitably produces a more or less high rate of false positive results and can therefore lead to overdiagnosis and therapy [21, 22]. During screening, the PPV and NPV are of particular importance for the subject to interpret the results. Measurement of TPA shows good data in the ROC analysis and for sensitivity and specificity with a cut-off of $80 \mathrm{~mm}^{2}$, but at the expense of a significantly increased rate of false positive results with low PPV. A TPA of $80 \mathrm{~mm}^{2}$ is alarmingly high for 35 - 49 year old, but average for 55 - 64 year old [23]. Like many other risk scores, the PROCAM score is based only on the consideration of traditional risk factors such as age, gender, blood pressure, lipid values, smoking status etc., without taking into account the extent of atherosclerosis, which means that only $21 \%$ of those with a high risk were classified. Just like for the TPA method not taking into account the age-related plaque area and the maximum plaque thickness, the PPV with $19 \%$ is very low. The use of the PROCAM score means that the majority of those affected would not be treated with a statin. With a TPA 80 method, a large part of the sufferers are treated, but also many test subjects do not need statin. The best results (sensitivity $85 \%$, PPV 27\%) for the prediction of CAD are achieved if the extent of atherosclerosis in relation to age and the maximum plaque thickness are determined for risk stratification. 


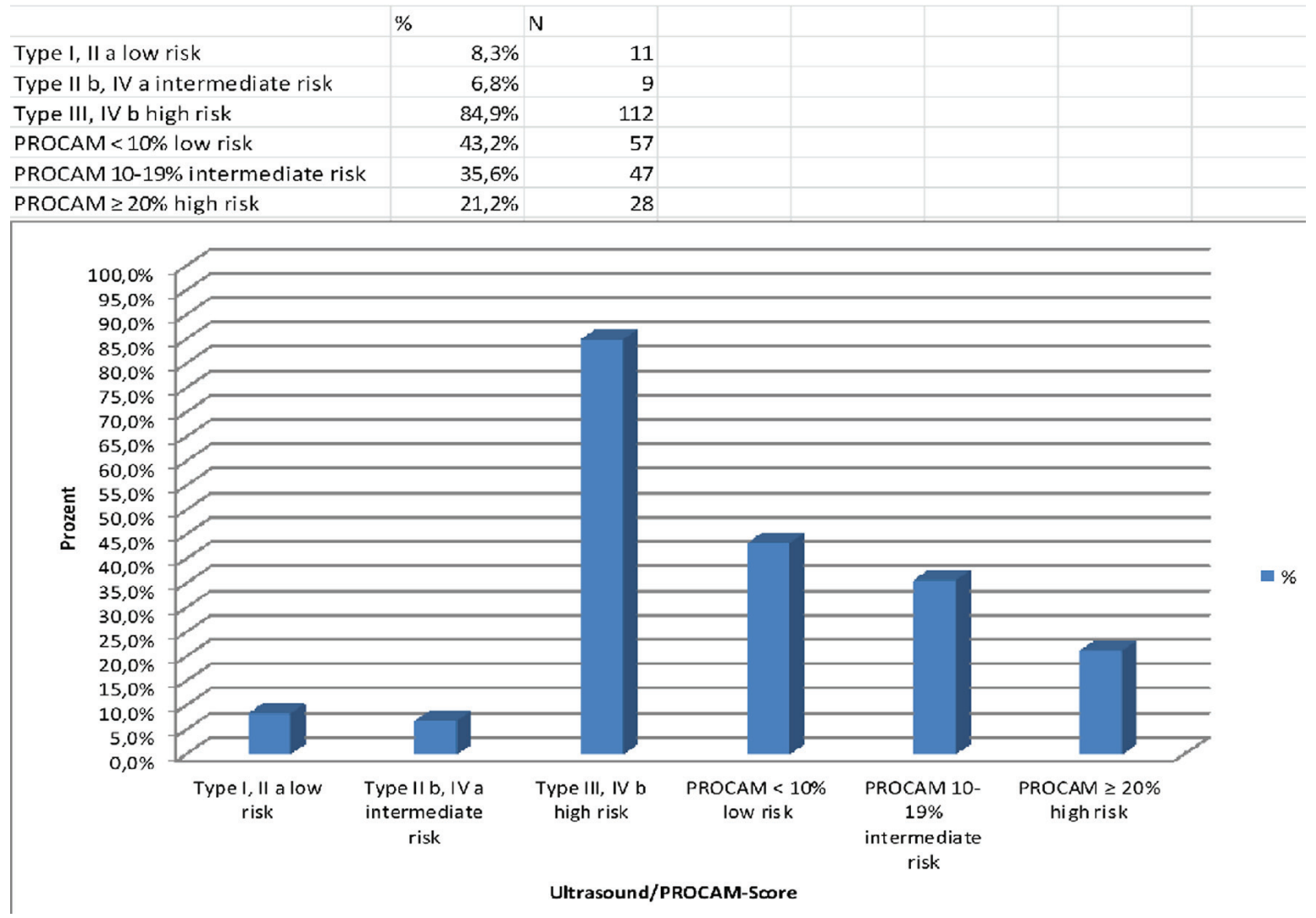

Figure 2. Distribution of patients with a cardiovascular event $(n=132)$ among risk categories defined by ultrasound and by PROCAM. PROCAM: the Prospective Cardiovascular Munster Study.

Confirmed coronary angiography findings were available in 297 subjects. In patients with a type III/IVb finding on ultrasound, the PPV for a coronary stenosis was $64 \%$, in one cut-off $\geq 30 \%$ stenosis a PPV of $76 \%$ and for a cut-off of sclerosis $88 \%$.
Several studies have shown that non-significant coronary artery stenosis is associated with an increased risk of heart attack [2427]. It therefore appears important to diagnose and treat atherosclerosis at an earlier, clinical asymptomatic stage in order to

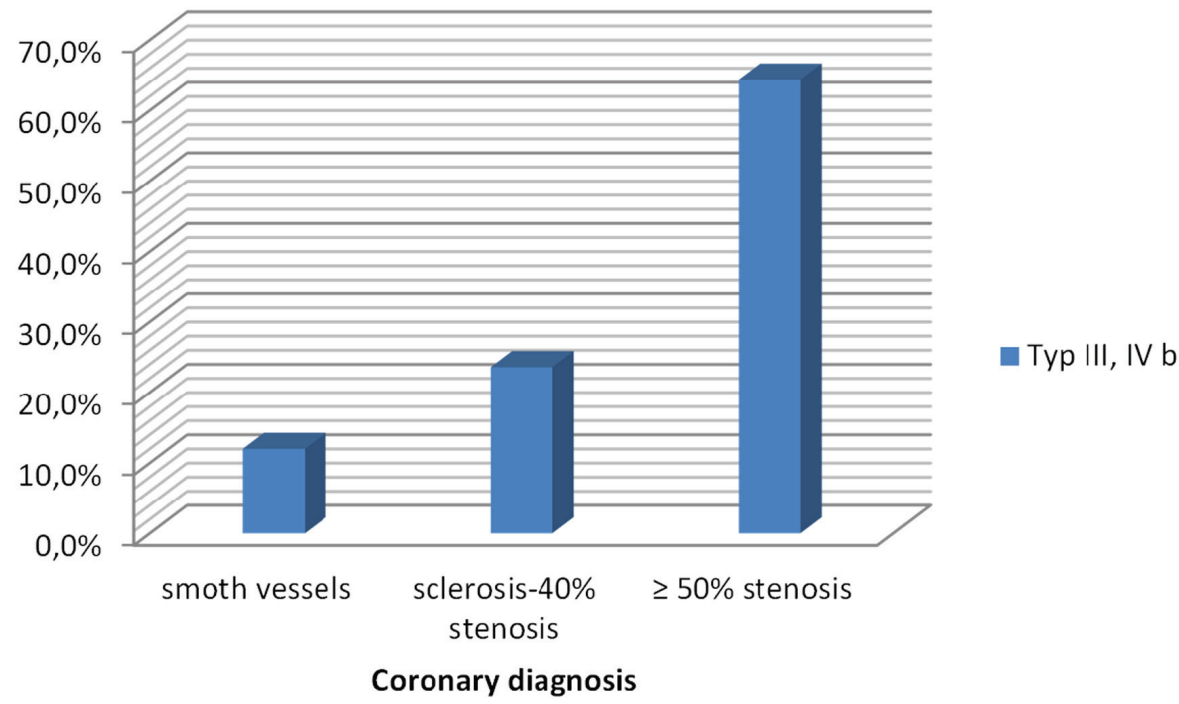

Figure 3. Coronary findings in the presence of a type III - IVb finding on ultrasound. 
avoid or postpone cardiovascular events.

Our follow-up examinations showed that progression of atherosclerosis rarely occurs with statin treatment; regression can often be measured. A statistical analysis of this has not yet been carried out so far in our institution. The follow-up examination of the sick patients showed that the vast majority $(85.4 \%)$ was not treated and was not detected with the PROCAM score. According to Assmann et al, 45\% of infarct patients had a low PROCAM risk [19]. In cardiovascular prevention, it therefore seems sensible not only to determine the risk factors, but to measure the extent of the disease, the atherosclerosis. In the European Society of Cardiology (ESC) guidelines subjects with carotid plaques are classified to have a very high risk, but without giving a quantification [28, 29]. This study with age-related cut-off values for the TPA, taking into account the maximum plaque thickness, could help to reduce over therapy.

\section{Conclusions}

The determination of the plaque burden on the carotid artery using the described method is inexpensive, in principle available everywhere, easy to carry out, without side effects and improves the prediction or the exclusion of a CAD compared to the plaque area measurement alone or the risk stratification with the PROCAM score. If there is no type III or IVb finding on ultrasound, the probability of CAD with an NPV of $99 \%$ is very unlikely. Advanced atherosclerosis should be treated with statins.

\section{Acknowledgments}

None to declare.

\section{Financial Disclosure}

This study has not been supported by any external funding.

\section{Conflict of Interest}

The authors declare that there is no conflict of interest.

\section{Informed Consent}

All patients provided informed consent.

\section{Author Contributions}

WB and MR discussed the approach and the findings of this study with AA intensively, and gave AA valuable feedback. All examinations as well as the statistical evaluation have been done by AA.

\section{Data Availability}

Any inquiries regarding supporting data availability of this study should be directed to the corresponding author.

\section{Abbreviations}

ROC: receiver operating curves; AUC: area under the curve; SE: sensitivity; SP: specificity; TPA: total plaque area (carotid plaque); PROCAM: the Prospective Cardiovascular Munster Study; CI: confidence interval; PPV: positive predictive value; NPV: negative predictive value; Prev: prevalence; CAD: coronary artery disease

\section{References}

1. Okahara A, Sadamatsu K, Matsuura T, Koga Y, Mine D, Yoshida K. Coronary artery disease screening with carotid ultrasound examination by a primary care physician. Cardiol Res. 2016;7(1):9-16.

2. Johri AM, Behl P, Hetu MF, Haqqi M, Ewart P, Day AG, Parfrey $B$, et al. Carotid ultrasound maximum plaque height-A sensitive imaging biomarker for the assessment of significant coronary artery disease. Echocardiography. 2016;33(2):281-289.

3. Belcaro G, Nicolaides AN, Ramaswami G, Cesarone MR, De Sanctis M, Incandela L, Ferrari P, et al. Carotid and femoral ultrasound morphology screening and cardiovascular events in low risk subjects: a 10-year followup study (the CAFES-CAVE study(1)). Atherosclerosis. 2001;156(2):379-387.

4. Johnsen SH, Mathiesen EB, Joakimsen O, Stensland E, Wilsgaard T, Lochen ML, Njolstad I, et al. Carotid atherosclerosis is a stronger predictor of myocardial infarction in women than in men: a 6-year follow-up study of 6226 persons: the Tromso Study. Stroke. 2007;38(11):28732880.

5. Spence JD, Eliasziw M, DiCicco M, Hackam DG, Galil $\mathrm{R}$, Lohmann T. Carotid plaque area: a tool for targeting and evaluating vascular preventive therapy. Stroke. 2002;33(12):2916-2922.

6. Brook RD, Bard RL, Patel S, Rubenfire M, Clarke NS, Kazerooni EA, Wakefield TW, et al. A negative carotid plaque area test is superior to other noninvasive atherosclerosis studies for reducing the likelihood of having underlying significant coronary artery disease. Arterioscler Thromb Vasc Biol. 2006;26(3):656-662.

7. Griffin M, Nicolaides A, Tyllis T, Georgiou N, Martin RM, Bond D, Panayiotou A, et al. Plaque area at carotid and common femoral bifurcations and prevalence of clinical cardiovascular disease. Int Angiol. 2010;29(3):216225.

8. Johnsen SH, Mathiesen EB. Carotid plaque compared with intima-media thickness as a predictor of coronary and cerebrovascular disease. Curr Cardiol Rep. 2009;11(1):21-27. 
9. Nambi V, Chambless L, Folsom AR, He M, Hu Y, Mosley $\mathrm{T}$, Volcik K, et al. Carotid intima-media thickness and presence or absence of plaque improves prediction of coronary heart disease risk: the ARIC (Atherosclerosis Risk In Communities) study. J Am Coll Cardiol. 2010;55(15):1600-1607.

10. Romanens M, Miserez A R, Ackermann F, Riesen W, Spence J D, Darioli R. Imaging as a cardiovascular risk modifier in primary care patients using predictor models of the European and international atherosclerosis societies. Kardiovaskulare Medizin. 2007;10:139-150.

11. Nambi V, Brunner G, Ballantyne CM. Ultrasound in cardiovascular risk prediction: don't forget the plaque! J Am Heart Assoc. 2013;2(2):e000180.

12. Polak JF, Szklo M, Kronmal RA, Burke GL, Shea S, Zavodni AE, O'Leary DH. The value of carotid artery plaque and intima-media thickness for incident cardiovascular disease: the multi-ethnic study of atherosclerosis. J Am Heart Assoc. 2013;2(2):e000087.

13. Mathiesen EB, Johnsen SH, Wilsgaard T, Bonaa KH, Lochen ML, Njolstad I. Carotid plaque area and intima-media thickness in prediction of first-ever ischemic stroke: a 10-year follow-up of 6584 men and women: the Tromso Study. Stroke. 2011;42(4):972-978.

14. Inaba Y, Chen JA, Bergmann SR. Carotid plaque, compared with carotid intima-media thickness, more accurately predicts coronary artery disease events: a metaanalysis. Atherosclerosis. 2012;220(1):128-133.

15. Rundek T, Arif H, Boden-Albala B, Elkind MS, Paik MC, Sacco RL. Carotid plaque, a subclinical precursor of vascular events: the Northern Manhattan Study. Neurology. 2008;70(14):1200-1207.

16. Baber U, Mehran R, Sartori S, Schoos MM, Sillesen H, Muntendam P, Garcia MJ, et al. Prevalence, impact, and predictive value of detecting subclinical coronary and carotid atherosclerosis in asymptomatic adults: the BioImage study. J Am Coll Cardiol. 2015;65(11):10651074.

17. Adams A, Bojara W. [Prediction of coronary artery stenosis by measurement of total plaque area and thickness versus intima media thickness of the carotid artery]. Herz. 2015;40(5):817-822.

18. Adams A, Bojara W, Schunk K. Early diagnosis and treatment of coronary heart disease in asymptomatic subjects with advanced vascular atherosclerosis of the carotid artery (Type III and IV b Findings Using Ultrasound) and risk factors. Cardiol Res. 2018;9(1):22-27.

19. Assmann G, Schulte H, Cullen P, Seedorf U. Assessing risk of myocardial infarction and stroke: new data from the Prospective Cardiovascular Munster (PROCAM) study. Eur J Clin Invest. 2007;37(12):925-932.

20. Lalkhen AG, McCluskey A. Clinical tests: sensitivity and specificity. Cont Ed Anaesth Crit Care \& Pain. 2008;8:221-223.

21. Bautsch W. Anforderungen und Bewertungen der Ergebnisse von Laboruntersuchungen. Dtsch Arztebl Int. 2009;106(24):403-406.

22. Spix C, Blettner M. Screening: part 19 of a series on evaluation of scientific publications. Dtsch Arztebl Int. 2012;109(21):385-390.

23. Adams A. Die Plaqueflache an der Arteria carotis: Ein besseres Tool fur die Risikostratifizierung in der Primarpravention als der PROCAM-Score oder die IMT-Messung. Arbeitsmedizin Sozialmedizin Umweltmedizin. 2015;50:53-57.

24. Proudfit WL, Bruschke VG, Sones FM, Jr. Clinical course of patients with normal or slightly or moderately abnormal coronary arteriograms: 10-year follow-up of 521 patients. Circulation. 1980;62(4):712-717.

25. Stone GW, Maehara A, Lansky AJ, de Bruyne B, Cristea E, Mintz GS, Mehran R, et al. A prospective naturalhistory study of coronary atherosclerosis. N Engl J Med. 2011;364(3):226-235.

26. Maddox TM, Stanislawski MA, Grunwald GK, Bradley SM, Ho PM, Tsai TT, Patel MR, et al. Nonobstructive coronary artery disease and risk of myocardial infarction. JAMA. 2014;312(17):1754-1763.

27. Chow BJ, Small G, Yam Y, Chen L, McPherson R, Achenbach S, Al-Mallah M, et al. Prognostic and therapeutic implications of statin and aspirin therapy in individuals with nonobstructive coronary artery disease: results from the CONFIRM (COronary CT Angiography EvaluatioN For Clinical Outcomes: An InteRnational Multicenter registry) registry. Arterioscler Thromb Vasc Biol. 2015;35(4):981-989.

28. Piepoli MF, Hoes AW, Agewall S, Albus C, Brotons C, Catapano AL, Cooney MT, et al. 2016 European Guidelines on cardiovascular disease prevention in clinical practice: The Sixth Joint Task Force of the European Society of Cardiology and Other Societies on Cardiovascular Disease Prevention in Clinical Practice (constituted by representatives of 10 societies and by invited experts) Developed with the special contribution of the European Association for Cardiovascular Prevention \& Rehabilitation (EACPR). Eur Heart J. 2016;37(29):2315-2381.

29. Mach F, Baigent C, Catapano AL, Koskinas KC, Casula M, Badimon L, Chapman MJ, et al. 2019 ESC/EAS Guidelines for the management of dyslipidaemias: lipid modification to reduce cardiovascular risk. Eur Heart J. 2020;41(1):111-188. 